\section{India's HIV-1 epidemic}

$\mathrm{A}^{\mathrm{f}}$ frica's HIV-1 epidemic has, appropriately, received global attention. However, India stands to experience the greatest increase in absolute number of HIV-1 cases in the coming decades. As of 2004, at least 5 million people in India have been infected. ${ }^{1}$ Preventive interventions to decrease sexual transmission of HIV-1 that focus chiefly on sex workers and their clients could greatly abate the growth of the epidemic.

\section{A horrific scenario}

India is in the position of the African continent 15 years ago. Within a year or two India may well surpass South Africa as the country with the greatest number of people living with HIV1/AIDS. Peter Piot, director of UNAIDS, states, "The future of the global epidemic is really at stake in India." With a population of 1 billion, large numbers of commercial sex workers, mobile male workers, a high prevalence of STDs, low reported condom use with nonregular partners and a low prevalence of male circumcision, India is set to experience an explosion of HIV1 cases. The official Indian government statistic of 5.1 million HIV-1-positive people is uncertain because large, reliable, population-based surveys have not yet been done. In 2002, the US National Intelligence Council projected 20-25 million people living with HIV-1 in India by 2010. ${ }^{2}$ The National AIDS Control Organization predicts only 9 million by that time. ${ }^{1}$ The most thoroughly researched and current mathematical models project the number of HIV-1infected adults at about 50 million by 2015 if no effective interventions are implemented.

\section{Sex work appears to drive} the HIV-1 epidemic in India

About $85 \%$ of HIV-1 cases are due to heterosexual contact.
Mathematical models suggest that one-half to three-quarters of all new HIV-1 infections are first- or second-generation infections due to sex work. ${ }^{3}$ The southern states represent only $30 \%$ of India's population but have about $75 \%$ of prevalent HIV-1 cases (Fig. 1, which shows HIV prevalence among pregnant women, illustrates this geographical distribution). The southern states are, paradoxically, the richer, more developed states in India. However, they have high levels of commercial sex work and migrant labour.

\section{A blueprint for control}

Theoretically, the Indian HIV-1 epidemic could be driven to below-current levels through prevention programs focused on female sex workers and their male clients. ${ }^{4}$ Slowing HIV-1 growth means interrupting its transmission. The most clearly effective preventive interventions against $\mathrm{HIV}-1$ are those targeting groups that - because of high rates of partner change, increased susceptibility to infection or both - are vulnerable. Peer-group interventions among sex workers to teach them about condom use, control of STDs and client negotiation skills are highly effective. ${ }^{4} \mathrm{~A}$ program begun in Kolkata (formerly Calcutta) in the early 1990s called the Sonagachi Project focused on providing female sex workers with the tools to organize and protect themselves, and their clients, from becoming infected with HIV-1. From 1992 to 1999 condom use among sex workers in Kolkata increased from $3 \%$ to $90 \%$. As a result, Kolkata has not seen the rapid growth of HIV-1 in these populations that has been seen in other Indian cities (Fig. 2). ${ }^{5} \mathrm{~A}$ small nonrandomized trial of similar peer-group interventions showed significant increases in overall and consistent condom use among female commercial sex workers in the intervention area. ${ }^{5}$

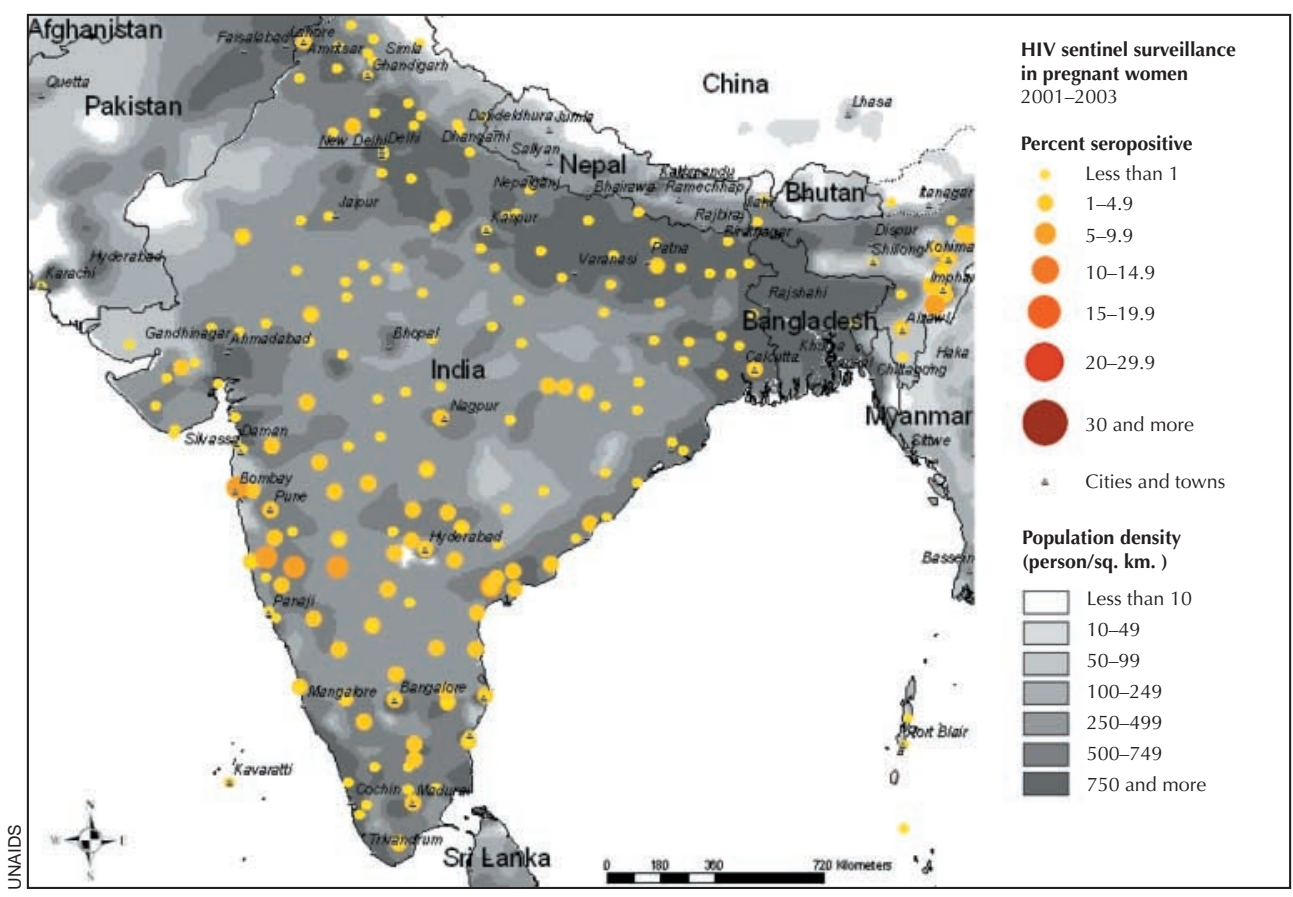

Fig. 1: India's HIV-1 epidemic is concentrated in the southern states. [Reproduced from the UNAIDS/WHO Epidemiological Fact Sheet - 2004 update: India; available: www.who.int/ GlobalAtlas/PDFFactory/HIV/EFS_PDFs/EFS2004_IN.pdf] 


\section{Large scale prevention}

The Bill and Melinda Gates Foundation has committed US\$200 million to the initial 5 years of the Avahan program to reduce HIV-1 and STD transmission in selected core populations in areas characterized by population mobility. The Avahan program focuses chiefly on 65 high-prevalence districts in 4 states: Karnataka, Andhra Pradesh, Tamil Nadu and Maharashtra. The target groups will be about 200000 sex workers and their clients, injection drug users, and men who have sex with men. The program will also focus on a 9000-km stretch of the Indian National Highway, where the target groups are approximately 1.5 million truckers and 30000 sex workers.

The Global Fund has approved US\$100 million to India to offer 7 million pregnant women, and their families, counselling to prevent HIV-1 infection, and $350000 \mathrm{HIV}-1$ infected pregnant women drugs to block mother-to-child transmission.

India can learn from the experiences of Thailand and Cam-

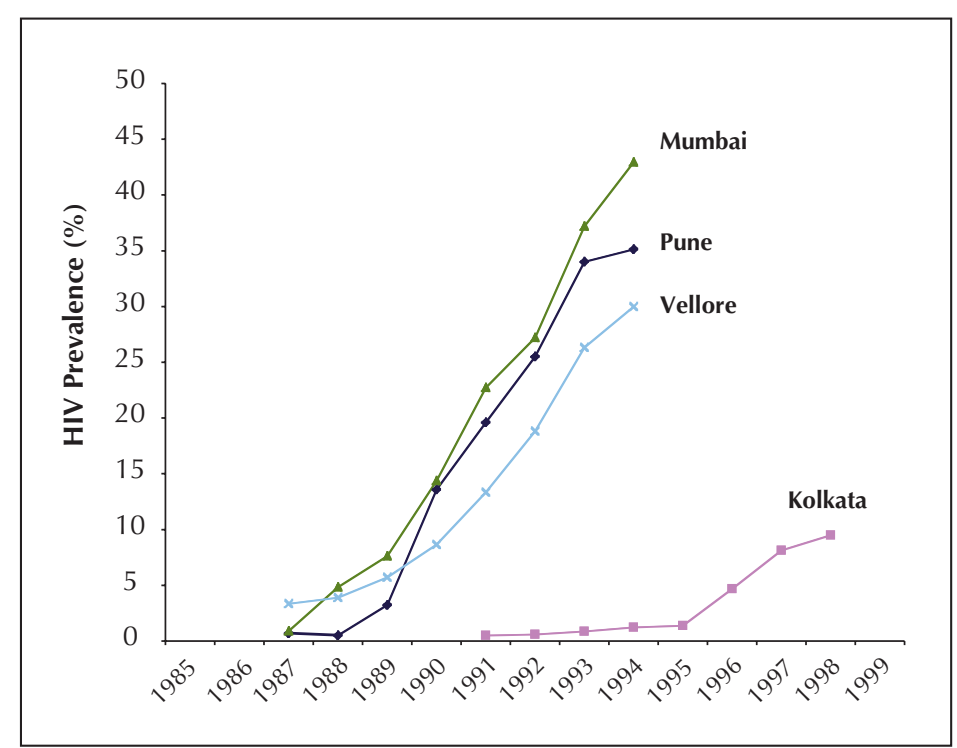

Fig. 2: Three-year rolling averages of seroprevalence of HIV-1 among commercial sex workers in India. The relatively low seroprevalence in Kolkata (formerly Calcutta) is attributed to the Sonagachi Project. (Note: NACO discontinued monitoring HIV-1 prevalence in sex workers after 1998.) [Source: UNAIDS/WHO Epidemiological Fact Sheet — 2004 update: India] of next year. The World Health Organization's "three by five" campaign targets are greater: some 300000 Indians on antiretroviral drugs. However, questions of cost, proper training and infrastructure remain, as does the potential to offset positive trends in behaviour change. ${ }^{4}$

More research is needed in India in order to document the transmission of $\mathrm{HIV}-1$, the role of male circumcision and the impact of antiretroviral drugs on populations. Such research is best done in concert with a massive scale-up of effective prevention programs. ${ }^{4}$

Paul Arora

Ajitha Cyriac

Prabhat Jha

Centre for Global Health Research

St. Michael's Hospital

Department of Public Health

Sciences

University of Toronto

Toronto, Ont.

Acknowledgements: Paul Arora is supported by a Canadian Institutes of Health Research Canada Graduate Scholarship Master's Award.

\section{References}

1. National AIDS Council Organization (NACO). Available: www.nacoonline .org/facts_overview.htm (accessed 2004 Oct 22).

2. Gordon DF. Intelligence Community Assessment. The next wave of HIV/ AIDS: Nigeria, Ethiopia, Russia, India, and China. National Intelligence Council; 2002. Available: www.odci. gov/nic/special_nextwaveHIV.html (accessed 2004 Oct 24).

3. Nagelkerke NJ, Jha P, de Vlas SJ, Korenromp EL, Moses S, Blanchard JF, et al. Modelling HIV/AIDS epidemics in Botswana and India: impact of interventions to prevent transmission. Bull World Health Organ 2002;80 (2):89-96.

4. Jha P, Nagelkerke JD, Ngugi EN, Prasada Rao JV, Willbond B, Moses $\mathrm{S}$, et al. Public health. Reducing HIV transmission in developing countries. Science 2001;292:224-5.

5. Basu I, Jana S, Rotheram-Borus MJ, Swendeman D, Lee SJ, Newman P, et al. HIV prevention among sex workers in India. 7 Acquir Immune Defic Syndr 2004;36(3):845-52.

6. Ruxrungtham K, Brown T, Phanuphak P. HIV/AIDS in Asia. Lancet 2004;364:69-82.

7. Human Rights Watch. India: eviction of sex workers boosts HIV risk - dismantling of homes in Goa displaces HIVprevention measures. New York: Human Rights Watch; 2004. 